This is an Author's Accepted Manuscript of an article published in Women \& Health Vol 52

(8) pp 788-803 [5 $5^{\text {th }}$ Nov 2012] [copyright Taylor \& Francis], available online at: http://www.tandfonline.com/10.1080/03630242.2012.728190

\title{
Mechanistic and 'Natural' Body Metaphors and their effects on attitudes to hormonal contraception
}

A small, self-selected convenience sample of male and female contraceptive users in the United Kingdom (UK) $(n=34)$ were interviewed between 2006 and 2008 concerning their feelings about the body and their contraceptive attitudes and experiences. The interviewees were a sub-sample of respondents $(n=188)$ who completed a paper-based questionnaire on similar topics, who were recruited through a poster, placed in a family planning clinic, web-based advertisements on workplace and university websites, and through direct approaches to social groups. The bodily metaphors used when discussing contraception were analyzed using an Interpretive Phenomenological Analytical approach facilitated by Atlas-ti software. The dominant bodily metaphor was mechanistic i.e. 'body as machine'. A subordinate but influential bodily metaphor was the 'natural' body, which had connotations of connection to nature and a quasisacred bodily order. Interviewees drew upon this 'natural' metaphorical image in the context of discussing their anxieties about hormonal contraception. Drawing upon a 'natural', non-mechanistic body image in the context of contraceptive decision-making contributed to reluctance to use a hormonal form of contraception. This research suggests that clinicians could improve communication and advice about contraception by recognizing that some users may draw upon non-mechanistic body imagery.

Keywords: body image, contraception, mechanistic, metaphor, natural 


\section{Background}

Unplanned pregnancy remains a significant problem in the developed world, despite the availability of effective contraceptive methods. The gap between the very small numbers of pregnancies conceived by users of short-term hormonal contraceptive methods during perfect use (approximately 3 per thousand per year) and those conceived during 'typical' use (approximately 80 per thousand per year) suggests that sociological and psychological, not biological factors, play a part in the apparent failure of many couples to prevent unwanted and unplanned conception (Trussell 2009)

\section{Discourse and the construction of body images}

Discursive insights suggest that the images and metaphors that we use to comprehend the physical and social world around us shape our understanding of that world (Johnson 1987; Angus et al. 2005). Although prominent in sociological research into health and illness, this social and linguistic understanding of our actions has been largely neglected in the clinical practice of biomedicine. Discursive approaches to health and illness are concerned with the effects of dominant constructions of reality (e.g. Foucault 1970). Particular constructions of reality are presented and enforced in the language used to talk about the 'real' world including biomedicine, its objects and its practices. One aspect of this construction is the imagery used in the metaphorical descriptions of objects and events.

The construction of the human body in biomedical discourse, through the use of unacknowledged imagery and metaphor, presents a particularly influential version of reality. Turner has defined the biomedical image of the body as having three specific properties: (a) the human body is a biochemical machine, (b) disease is a malfunction with a specific causal 
origin, (c) mind and body are distinct with disease located in the body (Turner 1995). This mechanical body imagery facilitates a secular, unemotional and instrumental approach to the manipulation of the body using biomedical technology. The 'body-as-machine' metaphor has also been noted in lay accounts of health and illness in the contexts of body maintenance and technological 'fixes'(Rogers 1991).

Contraceptive decisions involve the negotiation of metaphorical constructions of the body, implicit in biomedical explanations and information, encountered by the contraceptive user within the clinical setting. This study focused on the metaphors drawn upon by contraceptive users when talking about their bodies and considers how these might relate to dominant biomedical metaphors, and the connotations they evoke. Images and metaphor convey the 'working models' of the body which lie behind more explicit feelings about and understandings of the body and its interaction with the material and social world.

Metaphorical conceptualisations drawn upon by patients have been used to explore doctorpatient relationships and to explore women's body imagery with respect to osteoporosis (Rees et al. 2007; Reventlow 2008).

Martin (1987) contrasted metaphor and imagery, used to describe women's reproductive bodies within biomedicine, with images constructed by women themselves. She suggests that the way the body is 'imagined' profoundly affects the subjective experiences of women and their interactions with biomedicine.

The present research explored:

(a) What kind of bodily metaphors are used by users of contraception when discussing their own bodies?

(b) Whether the bodily metaphors used appear to affect contraceptive behavior? 


\section{Methodology}

\section{Ethical Approval}

Ethical permission was obtained from the local National Health Service Research Ethics Committee and from the relevant University Faculty Research Ethics Committee. Written informed consent was obtained from all participants prior to interview. Participants were informed that the research sought to explore connections between how people think about and experience their bodies, and their attitudes and feelings towards contraception.

\section{Participants}

The participants were self-selected and drawn from a larger sample of 188 respondents who had volunteered to complete a paper questionnaire on similar topics. Questionnaire respondents were recruited through a poster in a family planning clinic, by advertisement on two university websites and by approaches to workplaces and social groups in the area. The eligibility criteria were intentionally broad. The advertisements used to recruit made clear that respondents were eligible to participate in the study if they were current or previous users of contraception and were aged eighteen years or over. The questionnaires were picked up anonymously and returned by post, in pre-paid self-addressed envelopes. Due to the selfselected nature of the sample, it is not possible to know the eligibility rate of the population exposed to the advertisements, or to assess their eligibility at the point at which they took a questionnaire. The response rate for questionnaires was $46 \%$ (188/412), with the denominator expressing the number of questionnaires taken away but not returned.

On completion of the questionnaire respondents were asked to leave their names and contact details if they were willing to be interviewed. The same eligibility criteria were used for the interview portion as for the questionnaire sample. Eligibility for interview was assessed by 
the researcher prior to and during the invitation process. These respondents were contacted by the researcher sequentially and invited to interview if they were still willing to participate. Forty-two percent $(78 / 188)$ of those returning the questionnaires indicated that they were willing to be interviewed (Males $=44 \%(24 / 54)$, Females $=40 \%(54 / 134))$. Twenty-one female volunteers were contacted for interview. One was ineligible because she was aged less than eighteen years, and four declined or failed to reply. The eligibility of those with whom contact was made was 94\% (16/17). Twenty male volunteers were contacted for interview, and two declined or failed to reply. The eligibility of those contacted was $100 \%(18 / 18)$.

Recruitment of female participants stopped after 16 interviews when it was felt that thematic saturation had been achieved. Recruitment of male interviews continued with the aim of interviewing approximately equal numbers of men and women. Two more men (18) than women (16) were eventually interviewed due to the contingencies of arranging interviews and a desire not to refuse participants once they had agreed to interview. The interviewees were aged between 18 and 56 years (mean $=29.4$ years). All were resident in the East of England. All were current or previous users of contraception.

\section{Data Collection}

The interviews were semi-structured. They were carried out by the author in a university setting. Interviews were audio-recorded and transcribed. Interviewees were asked about how they imagined their own body in a general sense, and then more specifically about their feelings surrounding the body and contraceptive use. (A copy of the interview aide-memoire is available to readers on request).

Interviewees were also invited to draw a picture of their own body, which was discussed in 
the interview.

All names reported are pseudonyms.

Analysis

Interview analysis was undertaken based on an Interpretive Phenomenological Approach (IPA) as described by Smith (Smith et al. 1999). Atlas-ti software was used to aid coding. IPA has been widely used in health research in the last 15 years, especially in research looking at the body (Kay et al. 2009; Hargreaves \& Tiggeman 2006; Senior et al. 2002; Thompson et al. 2007; Wallace et al. 2007; Welsh \& Guy 2009).

Initially an in-depth reading of the first five of the 34 transcripts was undertaken making notes and comments by hand in the left-hand margin. To focus on the research topic, analysis involved only those areas of the transcripts which referred to the body, implicitly or explicitly. The initial detailed analysis of five transcripts was then used to guide the themes extracted from the remaining interview texts (Smith et al. 1999). The emergent themes from the initial five interview texts were used to search out and to categorize further quotations and concrete instances of these more abstract concepts in the remaining interview texts. New themes and further categorization and re-categorization continued as each new text was examined. In this way, shared themes were identified which were present in all or most of the interviews (Smith et al. 1999). Atlas-ti software was used to help with this subsequent coding. Atlas allows basic, primary codes to be created which are linked to words, lines, segments or paragraphs of text. This preliminary, primary coding resulted in over 500 separate codes.

The primary codes were grouped into areas which shared a common orientation, e.g. the body and food, the body and illness, the body and exercise, the body and pregnancy and so on. These became the shared, secondary themes of the interview texts. Primary codes could belong to more than one secondary group of codes, so, for example, the primary code "Whole foods" 
was assigned to the shared theme of "Body and food", and the shared theme of "Natural body". This grouping of primary codes into shared, secondary themes was facilitated by the use of the Atlas Network tool, which allows a pictorial representation of the linkages between codes to be built up on screen, so that codes belonging to more than one semantic grouping could be placed in a borderline position.

At this stage of the analysis, it was possible to use the secondary themes to produce a provisional collection of more abstract tertiary theme titles which were common to most of the texts examined. These were themes such as "Shame", "Control" and "Size/Weight". Further examination and refinement resulted in five final superordinate themes. These final five themes represented the images and metaphors of the body most salient to contraceptive use that were emerging from the interviews (Smith et al. 1999). For this paper only one of these super-ordinate themes was analyzed, that of mechanistic versus 'natural' metaphorical body imagery.

Table 1 (Supplementary file)

Examples of some of the Primary codes, the tertiary over-arching themes and the final five superordinate themes or body images to which they were eventually assigned are provided in Table 1. (The secondary codes are not shown because these existed only spatially as an artefact of the Atlas Network tool.)

\section{Results}

Female interviewees made up $47.1 \%$ of the study sample. The mean age of the entire sample was 29.4 years (Table 2). A high proportion (70.6\%) of participants had completed a college (university) degree or higher, and $61.8 \%$ reported being in a relationship of 3 months duration or longer; $23.5 \%$ reported having experienced unexpected pregnancy. Male 
interviewess were significantly more likely than female interviewees to have completed a college (university) degree ( $88.9 \%$ v. $50 \%$, Fisher's Exact test $\mathrm{p}=0.023)$. There were no significant differences between male and female interviewees in age $(U=111.5, p=0.259)$, percentage having experienced unexpected pregnancy (Fisher's Exact test, $\mathrm{p}=0.110$ ) nor percentage in a relationship of more than 3 months $\left(\chi^{2}(1)=0.389, p=0.533\right)$. The sample differed from questionnaire respondents who were not invited to interview in that the gender proportions were more equal and interviewees were less likely to report being in a relationship of 3 months or more duration (Table 2). The most frequently reported method of contraception used at last intercourse was a condom (35\%), followed by a contraceptive pill (21\%) (Table 3).

Table 2

Demographics of Interviewees $(n=34)$

Table 3

Contraceptive method used at last sexual intercourse

Two strong versions of metaphorical images of the body emerged. The dominant image was of the body as a machine, echoing the dominant biomedical imagery. A subordinate but influential image was of the 'natural' body. The term 'natural' encompassed a view of the body which was more holistic, personal and quasi-spiritual than the biomedical image. Sometimes both images were drawn upon at different times by the same interviewee. These images and variations of them fell at various points along an axis, which has a discrete, 
mechanistic, objective body at one end and an ecological, 'natural', subjective body at the other (Figure 1).

\section{Figure 1}

Mechanistic and 'Natural' Body Imagery

More men made use of a mechanistic bodily metaphor and more women of a 'natural' one, but the division did not occur along straightforwardly gendered lines. Some female interviewees, like Janet, used body metaphors which were very much at the 'natural' end of the spectrum. Others, like Anna drew on both metaphors at different times. Some male interviewees used highly mechanistic metaphors (Liam, Ezra) and others drew upon mixed mechanistic and natural metaphors.

For male interviewees, explicit or strongly mechanistic metaphors were used by $4 / 18$, implicitly mechanistic metaphors by $5 / 18$, and mixed metaphors by $5 / 18$. Neutral or no metaphors were used by 4/18. No female interviewee used strongly or explicitly mechanistic metaphors, an implicitly mechanistic metaphor was used by 1/16; mixed metaphors were used by 4/16; an implicitly 'natural' metaphor was used by $1 / 16$, and strong or explicitly 'natural' metaphors were used by $4 / 16$. Neutral or no metaphorical imagery was used by the remaining 6/16.

The next section shows how the trope of a mechanical and objectified body was drawn upon in different contexts and for different ends by interviewees.

\section{Body as Machine in context of Health and Illness}

The image of the 'body-as-machine' was expressed in the context of health and illness, and in particular with regard to illness as 'malfunctioning'. 
'But for me it's, it's a machine[...] It has parts and they are supposed to work together and sometimes they don't. (Laughs) But they are supposed to be and there are some things you can fix if they stop working together. And then you take medication or you go to the doctors.' (Anna; Aged 31-40 years).

\section{Body-as-Machine in the context of Performance}

Machine-like images of the body were expressed by some men in the context of control and performance.

'When I think of my body I think about it as something I'm supposed to look after, like a machine. It will do, it will work very well but only if I look after it.' (Ezra; Aged 31-40 years).

'I just think now I conceive my body as a machine really. So it really I think it's totally under my control.' (Liam; Aged 21-30 years).

\section{Connected to the wider, natural world}

The image of the body as part of the natural world was expressed in the body drawings of some female interviewees, in which the theme of nature was frequently represented. The 'natural' body appeared as an image in the interviews of both men and women, but was found more frequently in the interviews with women.

Interviewer;'Yea. I loved your pictures [of your body]. I thought they were great. Em, tell me a bit more about the apple then. Why is that you?'

$\mathrm{J}$; 'Em, the apple. Cos I like to think of myself as something that is part of nature. Like an apple is. And something I think apples should be cherished and enjoyed and I think they're round and smooth and I like [...], have that kind of positive image of my body when I'm in a good mood. That I'm like curvy and smooth' (Janet: Aged 21-30).

Figure 2 
Interviewer; 'I loved your picture [of your body]. I thought it was very cheerful. Do you want to...just tell me a wee bit about it?'[...]

K; 'I mean the smile, the happy...the almost that was life, yea. Kind of all around. Yea? Say part of the natural world. What's going on all around me' (Kezia; Aged 51+).

Figure 3

\section{The 'Natural' Body and the effects of Hormonal Contraception}

Female interviewees frequently referred to 'balance', 'interference', 'natural processes' and 'normal function' in their references to the effect of contraception upon the body and in their constructions of a good and healthy body. The use of hormonal contraception, in particular, was reported to "mess with" the natural balance of the body.

P; 'I have tried the pill a couple of times and...I don't like the fact that your body is full of chemicals and it made me very over-emotional about things. And I don't really like the fact that you're taking, that you're messing with your hormones all the time. So I guess yes, maybe because I'm into alternative things and maybe that's another reason I don't particularly like the idea.' (Paula; Aged 31-40 years).

A; 'I hate contraception.[...] I find it deceptive. It's, yea, it's not good. I hate the hormones. I hate to swallow hormones for something that [...] I like contraception as a concept. Absolutely. But I hate the mechanics and the implications that comes with it. So I have to get that straight. The concept of protected sex is simply that, of course, I embrace very much but I don't like the interference with my body in that sense cos I always suffer [...] That's the problem. You are just fighting nature the whole time' (Anna; Aged 31-40 years).

For interviewees who used the image of the natural body, non-hormonal contraception was often preferred. Anna continued; 
A; 'If I had, if the coil would have agreed with me then I would have liked it a lot more. Any mechanical barrier to me is better than hormones.'

Interviewer; 'Because it doesn't upset the...'

A; 'The hormone balance. Yea, and you, you actually just stop the sperm getting to the egg so you, we have a barrier somewhere so in that sense you don't interfere with the body functions. They still function normally.' (Anna; Aged 31-40 years).

Janet also expressed a 'natural' body image, in which the human body was part of the wider natural world and as a result should not be subjected to interference with its natural cycles.

'Yea, I don't like the idea[of taking hormones] because [... ] as a human being we're very part, much part of kinda nature like everything else is on this planet and I think [...] messing with your natural cycle is $[\ldots]$ I' $m$ uncomfortable with that idea[...] I feel I should be leaving it [the body] to do what nature intends it to do.' (Janet; Aged 21-30 years).

Within sections of the interview texts espousing a 'natural body', biomedicine was constructed as powerful but interventionist and thus a disruptor of the natural order of nature and of the body. The use of biomedical interventions to control fertility was viewed as overly disruptive to the natural order of the body. The disruption of the menstrual cycle by some forms of hormonal contraception was viewed negatively and created anxiety in this respect.

The concern not to intervene unnecessarily in bodily functions had the potential to affect contraceptive behavior. This was illustrated by Janet who expressed discomfort regarding her present form of contraception.

'And I'm really really bad at taking the mini-pill as well. I know that just every time I have to pick up that tablet and put it in my mouth, I feel really uncomfortable with it. So, you know I end up kind of not doing it for very long.' (Janet; Aged 21-30 years). 
Similarly, Olive disliked using regular contraception.

Interviewer; 'Do you think how you feel about your body influences how you feel about contraception? Do you see any link?'

O; 'I suppose so. I mean I've kind of stopped taking regular contraception because [...] I suppose cos I've always been quite healthy, I don't really like the idea of...as in oral contraception, I don't really like the idea of taking something every day. Because there's no need for me to do that. It's that kind of I'm not really a big one for medicine or doctors or anything like that so, yea, I suppose so. In that sense really it's influenced me'. (Olive; Aged 31-40 years)

Only one male interviewee invoked the trope of the 'unnaturalness' of interfering with bodily processes. He used it as an argument for not wishing to use a future male hormonal contraceptive pill.

'I'd, I would rather not use it because it would just alter the way my body works. That's why my partner doesn't use the implant or the pill. She told me that she once tried using the pill and [...]it had some effects that she didn't enjoy so she didn't use it any more and uh...well, as a result of having that conversation I then thought I would rather not mess around with my body and do unnatural things in that way. So I wouldn't really be very interested in the male pill.' (Martin; Aged 21-30 years).

\section{The Mechanistic Body and its Effects on Contraception}

In contrast a pragmatic, mechanical image of the body was credited with facilitating contraceptive use by one male interviewee.

$\mathrm{J}$; 'I guess I think of it as just being kind of mechanics so I guess maybe that makes a difference.[...] I guess I just would have a very pragmatic attitude towards the way your body functions and stuff. I wouldn't like think of it as being a special thing or a sacred thing or anything like that. So I guess it does make a bit of a difference' (Jacob; Aged 21-30 years). 


\section{Discussion}

\section{Main Findings}

A mechanized body image appeared conducive to viewing the intervention of contraceptive technology in a utilitarian manner, without fears of disrupting 'natural' rhythms of the body, which was viewed instead as a secular mechanism open to enhancement and manipulation. Mechanistic body metaphors resonated with the dominant metaphor of the body used by biomedicine (Turner 1995:2008)

In contrast, the sections of the interviews which constructed a body image which emphasized the natural and the sacred qualities of the body also expressed a distrust of hormonal contraceptive methods, because of the perceived disruption to the natural order of the body. The disruption of the menstrual cycle by hormonal methods was cited as evidence of this disrupted bodily order.

This study was not intended to seek out the roots of the division between mechanistic and 'natural' body imagery. Although gender appeared to play a part, other factors such as education, age, religiosity, health status and so on may also be relevant, and this is an area of research which needs to be further explored.

\section{Previous research findings}

Concerns over the side effects of hormonal contraception are a cause of discontinuation (Clark et al. 2006; Larson et al. 1997; Moreau et al. 2007, 2008; The ESHRE Capri Workshop Group 2000). However, the discursive constructions and metaphorical imagery involving the body underlying these concerns have been less studied. 
In keeping with the findings of this paper, Cheung \& Free (2005) specifically noted that the idea of a 'natural menses' and its disruption by hormonal contraception was a factor in some women stopping hormonal contraception.

In terms of communication in the clinical setting, Keogh (2005a) found that the different value placed upon the 'natural' body by users and providers of emergency contraception could impede effective communication. This study reinforces this and her finding that concerns about the 'natural' body and about the unnatural suppression of ovulation and menstruation may underlie choice of contraceptive method (Keogh 2005a, 2005b). This study illuminates the metaphorical images of the body, either 'natural' or mechanistic, which may have determined the extent to which women feel anxiety about contraception and its effects upon their fertility, and the choices they make (Keogh 2005b).

\section{Limitations of the study}

The sample used for these interviews was small, self-selected and largely well-educated current or prior users of contraception which limited its representativeness and thus the generalizability of the findings. Only $19 \%$ of female interviewees reported using the contraceptive pill as their main method of contraception at last intercourse. This is a smaller proportion than that reported nationally (28\%) and indicates that this sample may be unrepresentative in terms of its opinions on hormonal contraception (Lader \& Hopkins 2008).

Compared with questionnaire respondents who were not interviewed, the interviewees were less likely to be in an established relationship of more than 3 months, and the gender division between male and female was more equal. This is likely to have introduced some bias into the findings. 
The analysis was carried out by the author as a sole researcher as part of a $\mathrm{PhD}$ project. Thus, a second coder was not used to code independently each transcript. This lack of use of a quality control method for coding reduced the rigor of the analysis because it did not allow control the potential for subjective bias on the part of the coder. However the use of a well established analytical method (IPA) and reproduction of the steps of the analysis limited this bias. Nonetheless, the findings reported are necessarily a subjective analysis, and as such should be considered exploratory, and require confirmation by other researchers using a more objective and controlled approach as well as a larger, more representative sample of participants.

\section{Implications for Practice and Health Education}

In this study, the distrust of hormonal contraceptive methods and discomfort with their effects upon the 'natural' body was an area of dissonance between the mechanized biomedical body image implicit in biomedical language and texts and 'natural' lay images of the body, drawn upon at times in these interviews. This dissonance may not be recognized in the course of a clinical consultation and so may also be a potent cause of the reluctance or inability of some women to make use of hormonal contraceptive technologies effectively.

The recognition of this metaphorical and imaginative dissonance in the contraceptive consultation may allow a freer exchange of views between clinician and client, and help address some of the anxieties surrounding hormonal contraceptive methods. Greater use of and advice upon natural methods of contraception such as withdrawal and fertility timing (rhythm method) may be more effective in 'real world' terms, (despite their lower efficacy in ideal terms) for women, like Janet, who find that their distrust of hormonal methods leads to them discontinuing their use or using them ineffectively. 
Health education approaches cannot assume that potential contraceptive users share the dominant 'body as machine' image, drawn upon by educational materials and contraceptive information leaflets. 


\section{References}

Angus , J., S. Evans, J. Lapum, E. Rukholm, R. St Onge, R. Nolan, and I. Michel. 2005.

"Sneaky disease ": The body and health knowledge for people at risk for coronary heart disease in Ontario, Canada. Social Science \& Medicine, 60 (1982): 2117-28,

http://www.ncbi.nlm.nih.gov/entrez/query.fcgi?cmd=Retrieve \&db=pubmed\&dopt=Abstract\&li $\underline{\text { st uids }=15743659}$

Cheung, E., and C. Free. 2005. Factors influencing young women's decision making regarding hormonal contraceptives: A qualitative study. Contraception, 71 (6): 426-31.

Clark, Liana R., Kenyette T. Barnes-Harper, Kenneth R. Ginsburg, William C. Holmes, and Donald F. Schwarz. 2006. Menstrual irregularity from hormonal contraception: A cause of reproductive health concerns in minority adolescent young women. Contraception, 74 (3) (SEP 2006): 214-9.

Foucault, Michel. 1970. The order of things. an archaeology of the human sciences. (World of man.). London: Tavistock Publications.

Hargreaves , Duane,A., and Marika Tiggemann. 2006. ' Body image is for girls': A qualitative study of boys' body image. Journal of Health Psychology, 11 (4): 567-76, http://www.ncbi.nlm.nih.gov/entrez/query.fcgi? $\mathrm{cmd}=$ Retrieve $\& \mathrm{db}=$ pubmed\&dopt=Abstract\&list uids=16769736.

Johnson, Mark. 1987. The body in the mind: The bodily basis of meaning, imagination, and reason. Chicago: University of Chicago Press.

Kay, C. 2009. An exploration of the experiences of young women living with type 1 diabetes. Journal of Health Psychology, 14 (2) (Mar, 14 (2)): 242.

Keogh, L.A. 2005a. Understandings of the 'natural body': a comparison of the views of users and providers. Sexual Health 2 (2), 109-115 
Keogh, L. A. 2005b. Women's contraceptive decision-making: Juggling the needs of the sexual body and the fertile body. Women \& Health, 42 (4) (, 42 (4)): 83.

Lader, D. \& Hopkins, G. 2008. Contraception and Sexual health 2007/8. Omnibus survey report No. 37. Office for National Statistics.

Larsson, Gerd, Febe Blohm, Gunilla Sundell, Björn Andersch, and Ian Milsom. 1997. A longitudinal study of birth control and pregnancy outcome among women in a swedish population. Contraception, 56 (1) (7): 9-16.

Martin, Emily. 1994. Flexible bodies : Tracking immunity in American culture from the days of polio to the age of AIDS. Boston: Beacon Press.

1987. The woman in the body: A cultural analysis of reproduction. Beacon Press.

Moreau, C., J. Bouyer, N. Bajos, G. Rodriguez, and J. Trussell. 2008. Contraceptive discontinuation rates among french women: Frequency and reasons for stopping a method of contraception. Contraception, 78 (2) (AUG 2008): 186-.

Moreau, Caroline, Kelly Cleland, and James Trussell. 2007. Contraceptive discontinuation attributed to method dissatisfaction in the united states. Contraception, 76 (4) (OCT 2007): 267-72.

Rees, Charlotte E., Lynn V. Knight, and Clare E. Wilkinson. 2007. Doctors being up there and we being down here: A metaphorical analysis of talk about student/doctor-patient relationships. Social Science \& Medicine, 65 (4): 725-37.

Reventlow, Susanne, Iben Overgaard, Lotte Hvas, and Kirsti Malterud. 2008. Metaphorical mediation in women's perceptions of risk related to osteoporosis: A qualitative interview study. Health Risk and Society, 10 (2): 103.

Rogers, Wendy Stainton. 1991. Explaining health and illness: An exploration of diversity. New York ; London: Harvester Wheatsheaf. 
Senior, V., J. A. Smith, S. Michie, and T. M. Marteau. 2002. Making sense of risk: An interpretative phenomenological analysis of vulnerability to heart disease. Journal of Health Psychology, 7 (2): 157-68, http://dx.doi.org/10.1177/1359105302007002455.

Smith, J. A., M. Jarman, and M. Osborn. 1999. Doing interpretive phenomenological analysis. In Qualitative health psychology: Theories and methods., eds. M. Murray, Kerry Chamberlain, 218. London: SAGE.

The ESHRE Capri Workshop Group. 2000. Continuation rates for oral contraceptives and hormone replacement therapy. Human Reproduction, 15 (8) (August 01): 1865-71.

Thompson, Andrew,R., Gerry Kent, and Jonathan A. Smith. 2002. Living with vitiligo : Dealing with difference. British Journal of Health Psycholog,y 7 : 213-25, http://www.ncbi.nlm.nih.gov/entrez/query.fcgi?cmd=Retrieve\&db=pubmed\&dopt=Abstract\&list _uids=14596710.

Trussell, James. 2009. Understanding contraceptive failure. Best Practice \& Research Clinical Obstetrics \& Gynaecolog,y 23 (2) (4): 199-209.

Turner, Bryan S. 2008. The body and society : Explorations in social theory. Theory, culture \& society. 3rd ed. London: SAGE.

1995. Medical power and social knowledge, ed. Colin Samson. 2nd ed. London: Sage.

Wallace, Melissa,L., Diana Harcourt, Nichola Rumsey, and Annabel Foot. 2007. Managing appearance changes resulting from cancer treatment: Resilience in adolescent females. PsychoOncology, 16 (11): 1019-27, http://www.ncbi.nlm.nih.gov/entrez/query.fcgi? $\mathrm{cmd}=$ Retrieve $\& \mathrm{db}=$ pubmed\&dopt=Abstract\&list uids=17328096. 
Welsh, Nina \& Guy, Alison. 2009. The lived experience of alopecia areata: A qualitative study. Body Image, 6 (3): 194-200,

http://www.sciencedirect.com/science?_ob=GatewayURL\&_method=citationSearch\&_urlVersio $\underline{\mathrm{n}=4 \& \_ \text {origin }=E X L I B M E T A \& \_v e r s i o n=1 \& \_p i i k e y=S 1740-1445 \% 2809 \% 2900033-}$ $\underline{3 \& m d 5=6 c 9 b a f b 9191 e d 0 d 57 c 42656 c f 2 b 33 b 51}$ 